Krist V. Gernaey, Jakob K. Huusom and Rafiqul Gani (Eds.), 12th International Symposium on Process

Systems Engineering and 25th European Symposium on Computer Aided Process Engineering.

31 May - 4 June 2015, Copenhagen, Denmark (C) 2015 Elsevier B.V. All rights reserved.

\title{
Engineering Design of Localised Synergistic Production Systems
}

\author{
Melissa Leung Pah Hang, ${ }^{a}$ Elias Martinez-Hernandez, ${ }^{\mathrm{b}}$ Matthew Leach, ${ }^{\mathrm{a}}$ Aidong \\ Yang ${ }^{\mathrm{b}}$ \\ ${ }^{a}$ University of Surrey, Guildford and GU2 7XH, United Kingdom \\ ${ }^{b}$ University of Oxford, Oxford and OXI 2JD, United Kingdom
}

\begin{abstract}
Centralised production of essential products and services based on fossil fuels and large scale distribution infrastructures have contributed to a plethora of issues such as deterioration of ecosystems, social-economic injustice and depletion of resources. The establishment of localised production systems can potentially reduce unsustainable resource consumption and bring socioeconomic and environmental benefits. The main objective of this work is to develop engineering tools for the rational design of such systems. Production of services and products is characterised as inter-linked subsystems (e.g. food, energy, water and waste). A sequential design approach is developed to design subsystems in turn, with necessary iterations. The process is illustrated through the co-design of energy, water and food production for a case study locale based on a developing eco-town in the UK. This design approach suggested a highly integrated system based primarily on locally available resources and allowed greater insight into the drivers and constraints on local resource use.
\end{abstract}

Keywords: local production network, mathematical programming, resource consumption

\section{Introduction}

With the advent of industrialisation, the supply of energy and materials to meet human needs has been driven primarily by centralised production based on fossil fuels and large scale distribution infrastructures. However, continuation of this mode of production, coupled with rising economies and growing population, has led to a range of issues such as energy supply insecurity, deterioration of ecosystems, and depletion of resources. In response to these issues, localised production networks based on locally available resources have been advocated as one possible pathway towards sustainability (Middlemiss and Parrish, 2010; The Royal Academy of Engineering, 2011). A local production system is defined in this work as a network of heterogeneous processes, integrated in a synergistic manner to achieve a high degree of resource efficiency, potentially leading to improved economic viability while preserving the ecosystem (Martinez-Hernandez et al., 2014). Such a system contributes to improved prospects for closing loops as any wastes or by-products from production processes and used products from consumption will seek to be looped within the system through symbiotic arrangements. The aim of this work is to propose a systematic design approach for a local production system given a set of local demands by finding the combination of a set of locally available sources and processes which can meet such demands by minimising total resource consumption, while observing a set of ecological and technical constraints. The design approach has so far been developed by analyzing a specific case study. The learning from this particular case study may be generalised into a general 
framework for designing such localised production systems. The proposed approach is based on mathematical programming (MP) which has been widely applied in process systems engineering (Klatt and Marquardt, 2009; Klemes et al., 2013) to solve a wide range of problems such as the design of bioenergy network (Beck et al., 2008) and the synthesis of supply chains (Almansoori and Shah, 2012). The present work applies MP in a sequential and iterative approach for the integrated design of multiple production systems.

\section{Methodology}

Figure 1 presents the proposed framework for the co-design of food, water and energy network supported by a case study with reference to Whitehill and Bordon Eco-Town in the UK. The first step includes representing the components of the food, water and energy network and identifying the potential sources (i.e. supply of resource flow) and sinks (i.e. processes consuming the resource flows) in a superstructure. Mathematical models are then used to represent the processes (e.g. resource processing and conversion), constraints and interactions (i.e. exchange of flows). The least connected subsystem or network, i.e. the one upon which the other networks are least dependent is designed first in view of having a less constrained design problem. Food is considered the least connected network as energy and water are key resources for food production but both water and energy productions do not depend on food production in this particular case study. The water production network is assumed to be the second least connected network and is next designed while the energy production network is designed last. The objective function is to design the production network (food, water and energy) by selecting the production processes and determining the flow rates from source to sink that will minimise total resource consumption while observing a set of ecological and technical constraints for satisfying local demands. The objective function measured in terms of cumulative exergy resource consumption is calculated using the Cumulative Exergy Resource Accounting methodology (Leung Pah Hang et al., 2014).

The generic objective function for an individual production network was formulated as Eq. (1).

Minimise $\sum C E x C=\sum F_{\text {imp }} e_{i m p}$

Where,

$F_{\text {imp }}$ is the flow rate of imported flows to the production network (e.g. imported energy such as electricity from grid, heat from district heating, chemicals, fuels, fertilisers, imported animal feed);

$E_{\text {imp }}$ is the cumulative exergy consumption associated with the provisioning of the imported flows.

The optimisation is to be subject to the final local need, land availability, availability of local resource, balance between sources and sinks, concentration balance for water network, nutrient balance for food network and electricity and heat balances for energy network constraints. The optimisation model for each subsystem was solved using GAMS. Both the food and energy network were solved using linear programming while the water network was solved using non-linear programming due to non-linearity in its concentration balance. The sources and sinks considered for the three networks are shown in Table 1. 


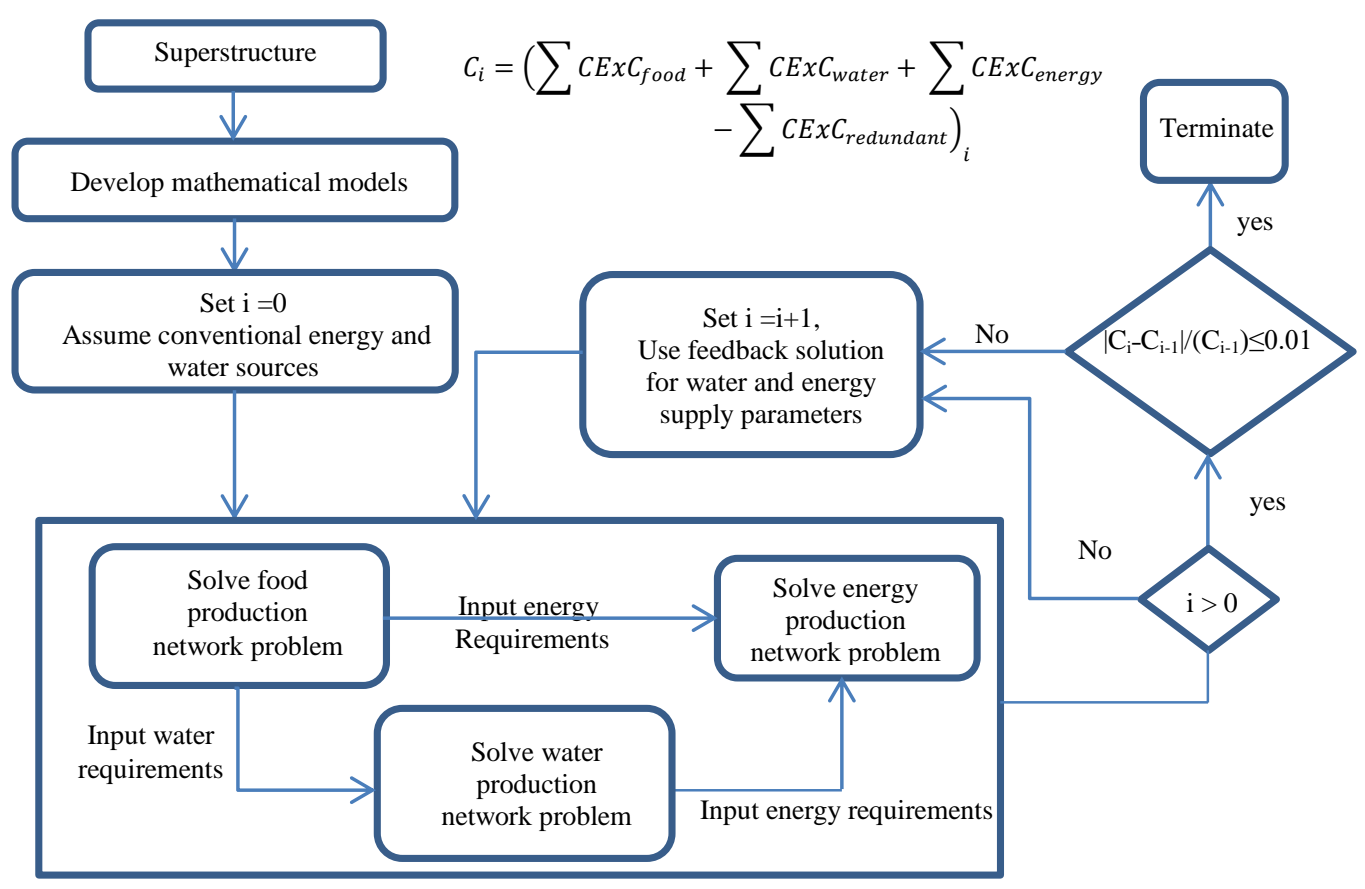

Figure 1: Methodological framework for co-design of food, water and energy network

The initial solution (i.e. $\mathrm{i}=0$ ) is obtained by solving the three production network design problems assuming conventional energy and water sources in the sequence as illustrated in Figure 1. The conventional energy sources are assumed to be electricity supplied from the grid and heat supplied from a natural gas based district heating network while groundwater is the conventional water source. First, the food production network is designed. Second, the water production network is designed by considering the water sources and sinks in the initial solution of the food production network, which will suggest specific water streams that can be used by the food production network and other local users and the associated resource costs in terms of the cumulative exergy content. Lastly, the energy production network is designed taking into account the energy sources and sinks in the initial solutions of the food and water production networks, to determine specific energy streams that can be generated locally or obtained from centralised supply to meet various demands including those from the food production network. For the next iteration $(\mathrm{i}=\mathrm{i}+1)$, the water and energy supply parameters from the previous iteration are used and the same sequence is repeated. The iteration stops when the cumulative exergy consumption to produce the streams exchanged between the three networks become stable, meaning that no further change is incurred by further iterations. This will be reflected in the overall cumulative exergy consumption for production of food, water and energy networks and can be verified using the criterion $\left|\mathrm{C}_{\mathrm{i}}-\mathrm{C}_{\mathrm{i}-1}\right| /\left(\mathrm{C}_{\mathrm{i}-1}\right) \leq 0.01$, as shown in Figure 1 . The cumulative exergy of the redundant flows refers to the exergy of the flows from the energy and water networks supplied respectively to the two other networks. 


\section{Results}

The initial results from the initial optimisation of the food network suggested that only bread and potatoes are produced locally. The objective function for the food production network was $1.04 \times 10^{8} \mathrm{MJ} / \mathrm{y}$. The initial results for the water network indicated that most of the water required by the water consuming processes is supplied by groundwater. A small portion of the wastewater generated during the bread processing is diluted by groundwater and used for both potatoes cultivation and processing. Similarly, a small amount of the wastewater produced from potatoes processing is also used together with groundwater for wheat cultivation and wheat processing into bread. The objective function for the water production network was $2.05 \times 10^{6} \mathrm{MJ} / \mathrm{y}$. The results generated from the initial optimisation of the energy production network showed that biomass CHP can supply all the electricity and heat demand of the food production network for production of potatoes and bread locally. Organic waste CHP can be used to satisfy the electricity requirements of the water production network while its process steam demand can be supplied by biomass CHP. Also, both the electricity and heat demands for households can be supplied partly by organic waste CHP and biomass CHP. The objective function for the energy production network was $1.09 \times 10^{9} \mathrm{MJ} / \mathrm{y}$. The objective function for the initial overall food, water and energy production network was about $1.20 \times 10^{9} \mathrm{MJ} / \mathrm{y}$.

Table 1: Sources and sinks in the food, water and energy production networks

\begin{tabular}{|c|c|c|c|}
\hline Sources & Sinks & Sources & Sinks \\
\hline \multicolumn{2}{|c|}{ Food production network } & \multicolumn{2}{|l|}{ Water production network } \\
\hline Imported fertiliser & $\begin{array}{l}\text { Wheat cultivation and } \\
\text { processing }\end{array}$ & $\begin{array}{l}\text { Treated food production } \\
\text { wastewater }\end{array}$ & $\begin{array}{l}\text { Energy } \\
\text { production }\end{array}$ \\
\hline $\begin{array}{l}\text { Imported animal } \\
\text { feed }\end{array}$ & $\begin{array}{l}\text { Potatoes cultivation } \\
\text { and processing }\end{array}$ & Wheat processing & Wheat cultivation \\
\hline Manure from cattle & $\begin{array}{l}\text { Cattle breeding and } \\
\text { processing }\end{array}$ & Potatoes processing & Wheat processing \\
\hline Manure from pigs & $\begin{array}{l}\text { Pig breeding and } \\
\text { processing }\end{array}$ & $\begin{array}{l}\text { Cattle breeding and } \\
\text { processing }\end{array}$ & $\begin{array}{l}\text { Potatoes } \\
\text { processing }\end{array}$ \\
\hline Wheat residues & - & $\begin{array}{l}\text { Pig breeding and } \\
\text { processing }\end{array}$ & $\begin{array}{l}\text { Cattle breeding } \\
\text { and processing }\end{array}$ \\
\hline Potatoes residues & - & $\begin{array}{l}\text { Treated domestic } \\
\text { wastewater }\end{array}$ & $\begin{array}{l}\text { Pig breeding and } \\
\text { processing }\end{array}$ \\
\hline \multicolumn{2}{|c|}{ Energy production network } & Groundwater & Residential water \\
\hline Grid & $\begin{array}{l}\text { Wastewater treatment } \\
\text { plant }\end{array}$ & Rainwater & Discharge \\
\hline Wind & $\begin{array}{l}\text { Food production } \\
\text { network }\end{array}$ & $\begin{array}{l}\text { Treated wastewater from } \\
\text { energy production }\end{array}$ & - \\
\hline Solar & Residential & & \\
\hline Biomass CHP & - & & \\
\hline Natural gas CHP & - & & \\
\hline
\end{tabular}

The $1^{\text {st }}$ iteration involves feeding back into the food production network the initial results from the optimisation of the water and energy production networks. The exergy parameter for energy used for the optimisation of the food production network now changed from $2.50 \mathrm{MJ} / \mathrm{kg}$ bread to $5.78 \mathrm{MJ} / \mathrm{kg}$ bread and for water use from 108.60 $\mathrm{MJ} / \mathrm{kg}$ bread to $107.90 \mathrm{MJ} / \mathrm{kg}$ bread. The parameter for energy use for potatoes changed from $0.41 \mathrm{MJ} / \mathrm{kg}$ potatoes to $0.81 \mathrm{MJ} / \mathrm{kg}$ potatoes and for water use from $1.13 \mathrm{MJ} / \mathrm{kg}$ 
potatoes to $1.12 \mathrm{MJ} / \mathrm{kg}$ potatoes while the parameters used for beef and pork production remains unchanged. These changes in parameters now resulted in only potatoes and pork being produced locally; indicating that the food production network is highly sensitive to the water production network and especially to the energy production network. The new objective function for the food production network after the $1^{\text {st }}$ iteration (i.e. the round following the initial optimisation) was $1.05 \times 10^{8} \mathrm{MJ} / \mathrm{y}$ which is $0.18 \%$ more than the initial value of the objective function. This is due to the use of biomass wood chip CHP where the biomass has a relative high cumulative exergy associated with its production and supply to the CHP. However, there is now more potential for a locally integrated food production network based on locally available resources. The manure from pig is used to partly satisfy the nutrient requirements of potato cultivation. Also, all residues from potato cultivation are now being used as animal feed for pigs. Groundwater consumption for food production has lightly decreased with exchanged water flows from bread and potatoes manufacture being used to supply part of the network's water requirements. Moreover, the resulting integrated food production network is not dependent on imported fossil fuels for its energy requirements. The objective function for the water production network for the $1^{\text {st }}$ iteration was $7.72 \times 10^{5} \mathrm{MJ} / \mathrm{y}$; a reduction of $62 \%$ from the initial objective function of the water production network, primarily due to rainwater replacing about $34 \%$ of the groundwater. The objective function of the energy production network from the $1^{\text {st }}$ iteration was $1.19 \times 10^{9} \mathrm{MJ} / \mathrm{y}$; an increase of $8.52 \%$ from the initial objective function of the energy production network as all energy demands are supplied by biomass CHP.

A further round of iteration was carried out, which led to a stabilised solution (the $3^{\text {rd }}$ iteration was run and gave similar solution to the $2^{\text {nd }}$ iteration). The final results are presented in Figure 2. The total potato demand and $11 \%$ of total pork demand can be satisfied locally; water is supplied by both groundwater and rainwater while electricity and heat are supplied locally by biomass wood chip CHP. The objective function for the overall production of food, water and energy was $1.29 \times 10^{9} \mathrm{MJ} / \mathrm{y}$; an increase of $7.7 \%$ from the initial overall solution. As compared to the initial solutions, the objective functions of the last iteration for food and energy production networks increased respectively by $0.20 \%$ and $8.5 \%$; these increases were partly compensated by the decrease in $62 \%$ of the objective function for the water production network.

\section{Concluding remarks}

This work has developed a sequential and iterative approach to the co-design of the integrated production of food, water and energy to satisfy local demands by making the use of locally available resources within technical and ecological constraints while minimising aggregated resource consumption. This design approach has proved to be useful in the analysis of intermediate results contributing to better insight and understanding of the localised production system; offering an added-value to practitioners as compared to designing these three production networks simultaneously. In practice, local situations may well impede the adoption of a simultaneous approach due to the incremental nature of knowledge and data acquisition and options gathering from various stakeholders, thus there is great value in enriching the understanding of the linkages between subsystems which is enabled by the sequential approach. In particular, it was useful in gaining insight, by means of the intermediate results obtained from the iterative process, on the balance of cumulative exergy consumption between the food, energy and water networks and the trade off in using imported flows and conventional sources of energy and water and using locally available resources. As a next step, a 
further comparison between this sequential approach and the simultaneous approach can be made, with the possibility of refining the current approach into a hybrid one to benefit from the advantages of both.

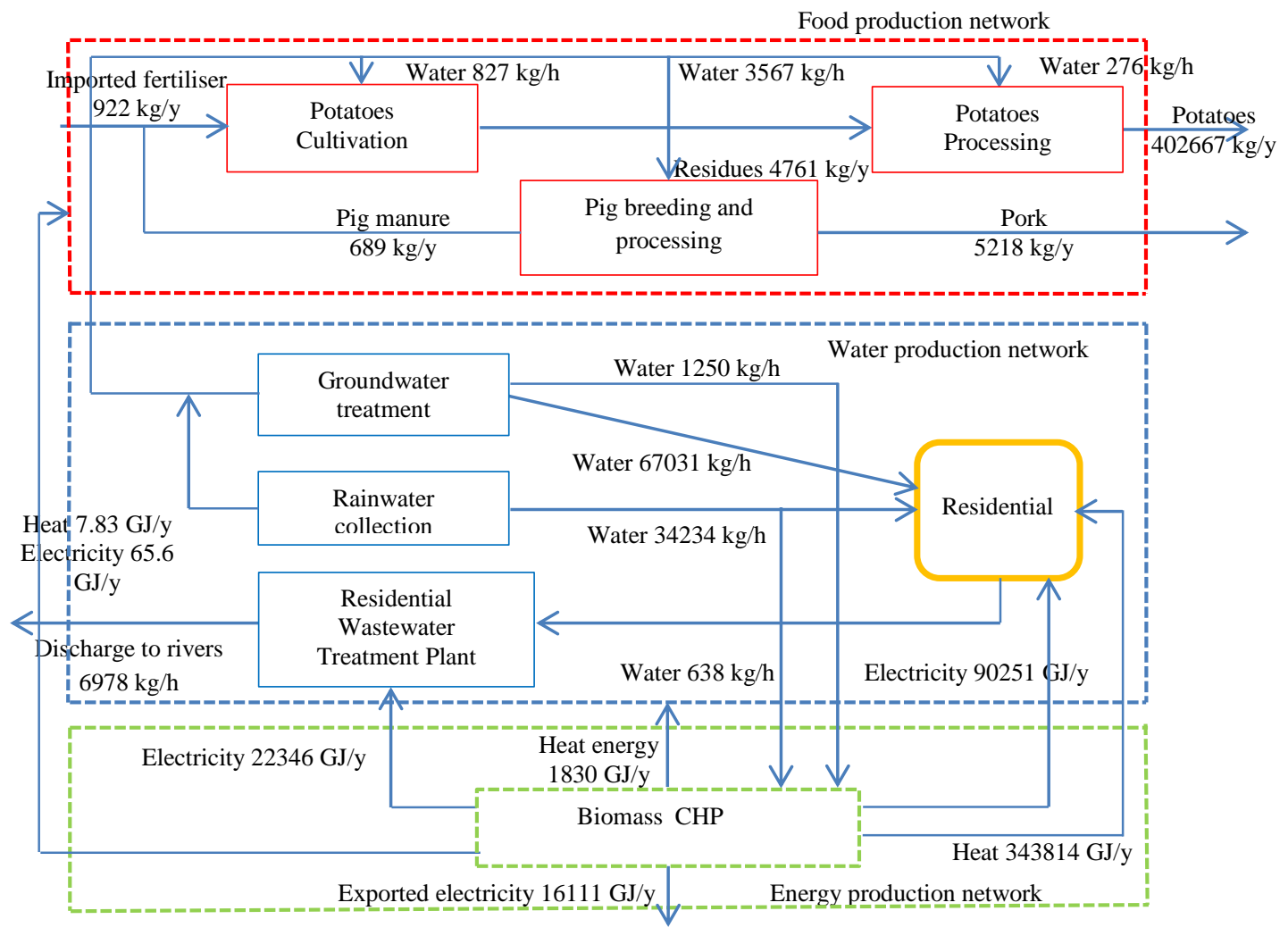

Figure 2: Detailed results for the last iteration

\section{References}

A. Almansoori, N. Shah (2012) Design and operation of a stochastic hydrogen supply chain network under demand uncertainty, International Journal of Hydrogen Energy, 37, 3965-3977.

J. Beck, R. Kempener, B. Cohen, J. Petrie (2008), A complex systems approach to planning, optimisation, and decision making for energy networks, Energy policy 36, 2795-2805.

K.U. Klatt, W. Marquardt (2009) Perspectives for process systems engineering-Personal views from academia and industry, Computers and Chemical Engineering 33, 536-550

J.J. Klemes, P.S. Varbanov, Z. Kravanja (2013), Recent developments in Process Integration, chemical engineering research and design 91 (2013) 2037-2053

M. Leung Pah Hang, E. Martinez-Hernandez, M. Leach, A. Yang (2014) A multi-level framework for resource accounting. 17th European Roundtable on Sustainable Consumption and Production, 14-16 Oct 2014, Portoroz, Slovenia.

E. Martinez-Hernandez, M. Leung Pah Hang, M. Leach., A.Yang (2014) Local Resource Calculator-a tool for assessment of local production system options. 17th European Roundtable on Sustainable Consumption and Production, 14-16 Oct 2014, Portoroz, Slovenia

L. Middlemiss, B.D. Parrish (2010) Building capacity for low-carbon communities: The role of grassroots initiatives, Energy Policy, 38, 7559-7566.

Royal Academy of Engineering (2011) Infrastructure, Engineering and Climate Change Adaptation -ensuring services in an uncertain future, ISBN 1-903496-61-6 grassroots initiatives, Energy Policy, 38, 7559-7566. 